Natividad Gutiérrez Chong luana Martinez Resendiz Francy Sará Espinosa

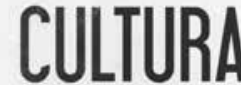
POLITICA INDÍGENA

Bolivia, Ecuador, Chile, México

UNivgusibad Nacional Autónoma de Méxić Instrtuto de Lsvesthescroses Socals
Indigenous Political Culture at the Level of Organizations

Marcela Meneses Reyes Instituto de Investigaciones Sociales, Universidad Nacional Autónoma de México,

Ciudad de México, México marcela.meneses@sociales.unam.mx

Desacatos 56 enero-abril 2018, pp. 190-193
- Cultura política indígena

NATIVIDAd GUTIÉRREZ CHONG,

JuANa Martínez ResÉndiz

Y FRANCY SARÁ ESPINOSA, 2016

Instituto de Investigaciones Sociales-

Universidad Nacional Autónoma

de México, México

\section{Cultura política indígena en el ámbito de las organizaciones}

\author{
MARCELA MENESES REYES
}

ste libro es una valiosa aportación al conocimiento y comprensión de una de las estrategias de participación política contemporánea de los pueblos indígenas en Latinoamérica, que consiste en la creación de organizaciones políticas encabezadas por líderes indígenas.

A partir de un proyecto de investigación a cargo de Natividad Gutiérrez Chong, investigadora del Instituto de Investigaciones Sociales (IIS) de la Universidad Nacional Autónoma de México (UNAM), en compañía de Juana Martínez Reséndiz, Francy Sará Espinosa y un equipo de asistentes, se creó una base de datos cualitativos recogidos en entrevistas a profundidad con líderes indígenas de 173 organizaciones, en México, Chile, Bolivia y Ecuador. De ahí se desprende el Sistema de Consulta de Organizaciones Indígenas y Conflictos Étnicos en las Américas (Sicetno), que a su vez se divide en otros dos sistemas: Conflictos Étnicos y Nacionalismos en las Américas (Cetna) y Organizaciones Indígenas de América Latina (Orgindal). Este último fue la materia prima para la elaboración del presente libro, prologado por Araceli Burguete Cal y Mayor, investigadora del Centro de Investigaciones y Estudios Superiores en Antropología Social-Sureste. 
El objetivo principal de Cultura política indígena radica en identificar en qué consiste la "política india" o "etnopolítica”. Las autoras utilizan de manera indistinta estos conceptos para referirse a "la forma en que los pueblos, a través de sus organizaciones y liderazgos, pretenden intervenir en la conducción de sus propios asuntos" (p. 28), en oposición a la falsa idea de que los indígenas son apáticos y se abstienen de participar de manera política. A esta crítica deberíamos oponer, en primer lugar, las preguntas de qué entendemos por política y cómo ésta se distingue de lo político, para retomar el viejo debate entre estos dos términos.

Si consideráramos la política sólo en sus formas institucionales, deberíamos partir del hecho de que en Latinoamérica ha imperado la exclusión de la población indígena de la toma de decisiones que marca el rumbo de los Estados-nación. Del mismo modo, si nos limitáramos al ejercicio de una democracia representativa ejercida por el voto en los comicios electorales, sería evidente que la diversidad de la población indígena, con sus múltiples necesidades, propuestas y demandas, tampoco quedaría representada por los partidos políticos, pues en general no incluyen a los pueblos indígenas en sus agendas, más que de forma demagógica para conseguir el "voto étnico" en época de elecciones.

Los testimonios de los líderes indígenas recogidos por Gutiérrez, Martínez y Sará nos permiten comprender su posición crítica respecto a la política institucional y de partidos. Las malas experiencias previas los han llevado a concluir que éstos sólo fragmentan y dividen a las comunidades, que no cumplen sus promesas y que se acercan a ellos para obtener el beneficio personal y del partido. Como resultado, se muestran renuentes a entablar más alianzas electorales, pues cuando lo han intentado han sido traicionados, como lo demuestran los conflictos actuales en Bolivia.

No obstante, las autoras señalan que aun cuando la vía del partido político no es la que ha seguido el activismo indígena:
Los pueblos indígenas no son reacios a participar de forma organizada, sino que las legislaciones no permiten reglas incluyentes en las que los pueblos indígenas y sus demandas son vitales para la construcción de política pública desde las dimensiones de la toma de decisiones, teniendo presentes sus prioridades y reconociendo las diferencias culturales sin que ello sea motivo de exclusión y discriminación (p. 88).

En el libro se exponen algunas excepciones, entre las que se encuentran el Movimiento de Unificación y Lucha Triqui (MULT), de México; el Movimiento al Socialismo, de Bolivia; el Partido PachakutikNuevo País, de Ecuador; el Partido Wallmapuwen —mapuche- de Chile, y el Yatama, de Nicaragua. Todos son partidos políticos indígenas que utilizan un nombre étnico y operan en una región determinada con la finalidad de buscar representatividad regional y nacional. Pugnan por la libre determinación, por la independencia de fuerzas políticas externas y por la configuración de canales institucionales para comunicar sus demandas sin intermediarios.

Una de las vías que la población indígena ha encontrado para participar en la política institucional, de manera más autónoma, ha sido la creación de organizaciones con objetivos diversos - políticos, culturales, ambientalistas, religiosos, de derechos humanos-, para satisfacer demandas y dar solución a sus problemas por medio de la gestión propia y sin intermediarios. Fue posible fortalecer esta forma organizativa en un contexto de coyuntura proclive a ello, es decir, en la década de 1990, cuando en Latinoamérica coincidió la conmemoración del Quinto Centenario, la declaración del Año de los Pueblos Indígenas por parte de la Organización de las Naciones Unidas, la firma del Convenio 169 de la Organización Internacional del Trabajo, la entrega del Premio Nobel de la Paz a la indígena quiché Rigoberta Menchú y el levantamiento zapatista de 1994. 
En general, en los cuatro países analizados se identificó que, a pesar de la gran heterogeneidad de percepciones que contienen las organizaciones indígenas latinoamericanas, todas demandan ser tomadas en cuenta, ser consultadas e incluidas en la toma de decisiones políticas de sus respectivos países y regiones. Sus características principales son: a) contienen una base étnica; b) están lideradas por intelectuales indígenas; c) afirman, reafirman o recuperan la identidad indígena, y d) presentan propuestas autonómicas.

Sus demandas principales consisten en la defensa de la tierra y el territorio; la protección de los recursos naturales; la preservación y respeto a la cultura, la identidad y la lengua; la oposición a la inversión nacional y extranjera en sus territorios; la creación de políticas educativas con enfoque intercultural, y la autonomía y la libre determinación. Sin embargo, más allá de sus similitudes, también es claro que no comparten una percepción o definición unificada sobre la autonomía, pues mientras algunas la sustentan como apuesta, otras la ejercen de facto.

Gutiérrez, Martínez y Sará desarrollan un elemento más: el uso que los pueblos indígenas están dando a los medios de comunicación alternativa por medio de las nuevas tecnologías. Con ellas ejercen el activismo cibernético y tejen redes de comunicación y solidaridad fuera de sus territorios. Con este mecanismo han logrado posicionar a sus organizaciones. Las autoras reconocen que el Ejército Zapatista de Liberación Nacional (EZLN) es el actor indígena pionero en la comunicación global, proceso que ahora se relaciona con en el cambio generacional para dar pie al activismo cibernético con fines de fortalecimiento de lo étnico. Empero, reconocen que el internet sigue siendo inalcanzable en muchas regiones de nuestros países, que no hay suficiente infraestructura tecnológica en las comunidades y que aún es inaccesible para millones de indígenas, por lo que puede resultar riesgoso exaltar el uso de las nuevas tecnologías como un medio estratégico de comunicación para los pueblos indígenas. Como señalan Charles Tilly y Leslie J. Wood (2010) en su amplio análisis de la historia de los movimientos sociales, las nuevas tecnologías sirven, sí, pero para conectar a los que de por sí están comunicados, lo que ensancha la distancia y la desigualdad entre los que tienen acceso a dichos medios y los que no.

Lo cierto es que en la actualidad los pueblos indígenas de Latinoamérica pugnan por dos demandas centrales en sus países: el derecho y el respeto a sus identidades y a la autonomía. En resumen, uno de los canales institucionales que ellos mismos han creado para participar políticamente es el de las organizaciones, cuya capacidad de incidencia es relativa, pero aun así están presentes y luchando por cambios acordes con su forma de mirar el mundo.

En las conclusiones, se plantean algunas preguntas pendientes que habrá que atender para dar continuidad a esta aportación: ¿cómo construir autonomías territoriales-regionales en las se puedan erigir autogobiernos locales? ¿Cómo intervenir en la toma de decisiones municipales o nacionales? ¿Qué vías existen para esto: los partidos políticos existentes o la creación de nuevos partidos que enarbolen su identidad étnica? Para las autoras, la vía de la protesta pacífica puede ser una respuesta a la renovación necesaria de la cultura política indígena con base en sus formas tradicionales de organización - usos y costumbres, asambleas, administración de recursos, etc.- - así como la creación de nuevos modelos de gobiernos locales y una nueva democracia participativa diferente a la representativa.

Desde mi perspectiva, sería importante ampliar el análisis acerca de la participación de las mujeres y los jóvenes en estas vías tradicionales de organización, con base en las transformaciones conflictivas que se presentan en este nivel de toma de decisiones. También sería pertinente explorar el papel de las organizaciones creadas por migrantes en lugares distintos a los de origen. Respecto a los medios de comunicación indígenas, habría que rastrear el impacto de la Ley 
Telecom, ${ }^{1}$ principalmente en las radios comunitarias. En cuanto a los líderes de las organizaciones indígenas, sería interesante construir sus trayectorias individuales y de grupo para identificar particularidades que permitan comprender su liderazgo en el marco de sus contextos de pertenencia. Por último, si las organizaciones requieren financiamiento para subsistir, ¿hasta dónde es viable mantenerse al margen de los recursos públicos y de los organismos internacionales en aras de la autogestión y la autonomía? ¿Será que al gestionar y aceptar financiamiento externo ceden parte de su libertad y capacidad de decisión? ¿Cómo colocarse frente a este dilema? D

La Ley Federal de Telecomunicaciones, conocida como Ley Telecom, promulgada en 2013, forma parte de las leyes secundarias de las reformas constitucionales impulsadas durante el sexenio 2012-2018 en México. Su objetivo es regular el uso del espectro radioeléctrico, las redes y los servicios de telecomunicaciones y radiodifusión.

\section{Bibliografía}

Tilly, Charles y Lesley J. Wood, 2010, Los movimientos sociales 1768-2008. Desde sus orígenes a Facebook, Crítica, Barcelona. 